\section{CC-chemokine ligand 18 is a useful biomarker associated with disease activity in IgG4- related disease}

IgG4-related disease (IgG4-RD) is a systemic disorder characterised by elevated serum IgG4 levels, tissue infiltration by IgG4 ${ }^{+}$plasma cells and severe fibrosis. ${ }^{12}$ However, biomarkers for IgG4-RD disease activity are lacking. ${ }^{3}$ A recent report demonstrated that CC-chemokine ligand 18 (CCL18) was a substantial biomarker for fibrotic diseases. ${ }^{4}$ Here, we investigated the correlation between serum CCL18 levels and clinical features of patients with IgG4-RD.

Written informed consent was obtained from all patients and healthy controls. Twenty-eight consecutive patients with active, untreated IgG4-RD diagnosed based on the 2011 comprehensive diagnostic criteria ${ }^{5}$ and 16 healthy controls were enrolled. Diagnosis of IgG4-RD was biopsy proven in 26 patients (93\%). Disease activity was assessed using the IgG4-RD responder index (IgG4-RD RI). ${ }^{6}$ Healthy controls had no autoimmune diseases, atopic diseases or active infections at enrolment. Serum CCL18 levels were measured using a human CCL18/ PARC Quantikine ELISA Kit (R\&D Systems, Minneapolis, Minnesota, USA).

Characteristics of patients are shown in table 1 . The mean age of patients with IgG4-RD and healthy controls was 59.7 and 47.3 years, and the proportion of females were $50 \%(14 / 28)$ and $69 \%(11 / 16)$, respectively.

Serum CCL18 levels in patients with IgG4-RD (median $44.5 \mathrm{ng} / \mathrm{mL}$, range $3.6-120.9 \mathrm{ng} / \mathrm{mL}$ ) were significantly higher than those in healthy controls (median $13.0 \mathrm{ng} / \mathrm{mL}$, range $0.1-63.8 \mathrm{ng} / \mathrm{mL} ; \mathrm{p}=0.01$ ) (figure $1 \mathrm{~A}$ ). The number of IgG4-RD patients with above normal levels of serum CCL18 (mean +1.96 SD of the healthy controls: $27.79 \mathrm{ng} / \mathrm{mL}$ ) was 17 (61\%), which was significantly higher than that of healthy controls $(n=3$, $19 \% ; \mathrm{p}=0.01)$. Of note, serum CCL18 levels were positively correlated with IgG4-RD RI score $(\rho=0.54, p<0.005)$, number of affected organs $(\rho=0.56, \mathrm{p}<0.005)$, serum IgG4 level $(\rho=0.50, p<0.01)$ and soluble Interleukin (IL) -2 receptor level $(\rho=0.56, p<0.005)$, but not serum IgE level $(\rho=-0.05$, $\mathrm{p}=0.79)$ or blood eosinophil count $(\rho=0.18, \mathrm{p}=0.38)$, suggesting that serum CCL18 level is associated with IgG4-RD disease status rather than allergic condition (figure $1 \mathrm{~B}, \mathrm{C}$ ). In line with this observation, serum CCL18 levels were similar between IgG4-RD patients with and without an atopic history (mean 47.8 vs $40.0 \mathrm{ng} / \mathrm{mL}, \mathrm{p}=0.51$; figure $1 \mathrm{D}$ ). There was no statistically significant correlation between specific organ involvement and higher serum CCL18 levels. Serum CCL18 levels significantly decreased after glucocorticoid treatment (44.7 ng/mL vs $12.7 \mathrm{ng} / \mathrm{mL}, \mathrm{p}<0.01$; figure $1 \mathrm{E})$ with declining disease activity (IgG4-RD RI: 12 vs $2, \mathrm{p}<0.01$ ).

Recent reports suggest that $\mathrm{M} 2$ macrophages are involved in the process of fibrosis. ${ }^{7}$ CCL18 is primarily secreted from activated M2 macrophages induced by T helper type 2-associated cytokines such as IL-4 and IL-13, ${ }^{8}$ and plays a role in the stimulation of collagen production by fibroblasts. ${ }^{9}$ Importantly, DNA microarray analysis showed that CCL18 was upregulated in IgG4-RD-affected tissues. ${ }^{10}$ Moreover, CCL18 expression was colocalised with massive infiltration of M2 macrophages and positively correlated with the fibrosis scores at affected IgG4-RD sites. ${ }^{7}$ Thus, CCL18 secreted by M2 macrophages plays a significant role in the fibrotic process in IgG4-RD.
Table 1 Characteristics of patients with IgG4-related disease

\begin{tabular}{|c|c|}
\hline \multicolumn{2}{|l|}{ Clinical parameters } \\
\hline IgG4-RD responder index, median (range) & $12(6-21)$ \\
\hline Serum lgG (mg/dl), median (range) & $1729(934-3593)$ \\
\hline Serum lgG4 (mg/dL), median (range) & $387.5(65-2178)$ \\
\hline Soluble IL-2 receptor $(\mathrm{U} / \mathrm{mL})$, median (range) & $448(202-1963)$ \\
\hline \multicolumn{2}{|l|}{ Atopic features } \\
\hline Past atopic history, n (\%) & $17(61 \%)$ \\
\hline Serum IgE (IU/mL), median (range) & $310(38-3300)$ \\
\hline Blood eosinophil count (cells/ $\mu \mathrm{L}$ ), median (range) & $231(62-1568)$ \\
\hline \multicolumn{2}{|l|}{ Organs involved } \\
\hline Number of affected organs, median (range) & $3(1-6)$ \\
\hline Lacrimal gland and orbit, $\mathrm{n}(\%)$ & $22(79 \%)$ \\
\hline Salivary gland, $\mathrm{n}(\%)$ & $19(68 \%)$ \\
\hline Lymph node, n (\%) & $16(57 \%)$ \\
\hline Lung, $n(\%)$ & $7(25 \%)$ \\
\hline Pancreas, n (\%) & $7(25 \%)$ \\
\hline Kidney, n (\%) & $5(18 \%)$ \\
\hline Retroperitoneum, n (\%) & $3(11 \%)$ \\
\hline Aorta, $\mathrm{n}(\%)$ & $2(7 \%)$ \\
\hline Skin, n (\%) & $2(7 \%)$ \\
\hline Breast, $\mathrm{n}(\%)$ & $1(4 \%)$ \\
\hline Paravertebral mass, $\mathrm{n}(\%)$ & $1(4 \%)$ \\
\hline
\end{tabular}

Our study has several limitations. For example, serum CCL18 levels after glucocorticoid treatment may be a direct result of the medication rather than being a secondary marker of disease activity like other biomarkers. To eliminate the possible confounding effects of glucocorticoids on the decline in CCL18 levels, further longitudinal studies in patients with relapsing or glucocorticoid-resistant IgG4-RD are required. Such studies can clarify whether a preceding elevation in serum CCL18 level is a predictive indicator for subsequent relapse of IgG4-RD activity in guiding treatment decisions.

In conclusion, our results indicate that CCL18 is a useful biomarker for evaluating not only the disease activity of IgG4$\mathrm{RD}$, but also patient response to therapy. Our data suggest that CCL18 may be a novel therapeutic target for IgG4-RD.

\section{Mitsuhiro Akiyama, Hidekata Yasuoka, Keiko Yoshimoto, Tsutomu Takeuchi}

Department of Internal Medicine, Division of Rheumatology, Keio University School of Medicine, Shinjuku-ku, Tokyo, Japan

Correspondence to Dr Mitsuhiro Akiyama, Division of Rheumatology, Department of Internal Medicine, Keio University School of Medicine, 35 Shinanomachi, Shinjukuku, Tokyo, Japan; hhhirooo@hotmail.com and Dr Tsutomu Takeuchi, Division of Rheumatology, Department of Internal Medicine, Keio UniversitySchool of Medicine, 35 Shinanomachi, Shinjuku-ku, Tokyo 160-8582, Japan; tsutake@z5.keio.jp

Acknowledgements We thank all the patients and healthy individuals who participated in this study. We would like to thank the staff of the Rheumatology Division of Keio University School of Medicine for treating the patients.

Contributors All authors were involved in the drafting of the article or critical revision of important intellectual content, and all authors approved the final version to be published.

Funding This study was supported by an institutional research grant from Keio University and by Mitsubishi Tanabe Pharma Company, Japan.

Competing interests MA has received consultancies, speaking fees and honoraria from Asahi Kasei Co, Cure Grades Co, and Eisai Co., and a research grant from Mitsubishi Tanabe Pharma Co. TT has received consulting fees, speaking fees and/or honoraria from Pfizer Japan, Mitsubishi Tanabe Pharma, Eisai, Astellas Pharma and UCB (less than \$10 000 each) and Chugai Pharmaceutical, Bristol-Myers K.K, Daiichi Sankyo, AbbVie, Janssen Pharmaceutical K.K, Pfizer Japan, Asahi Kasei Pharma, 
A

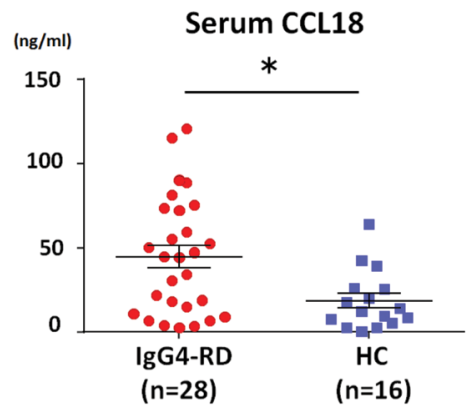

B
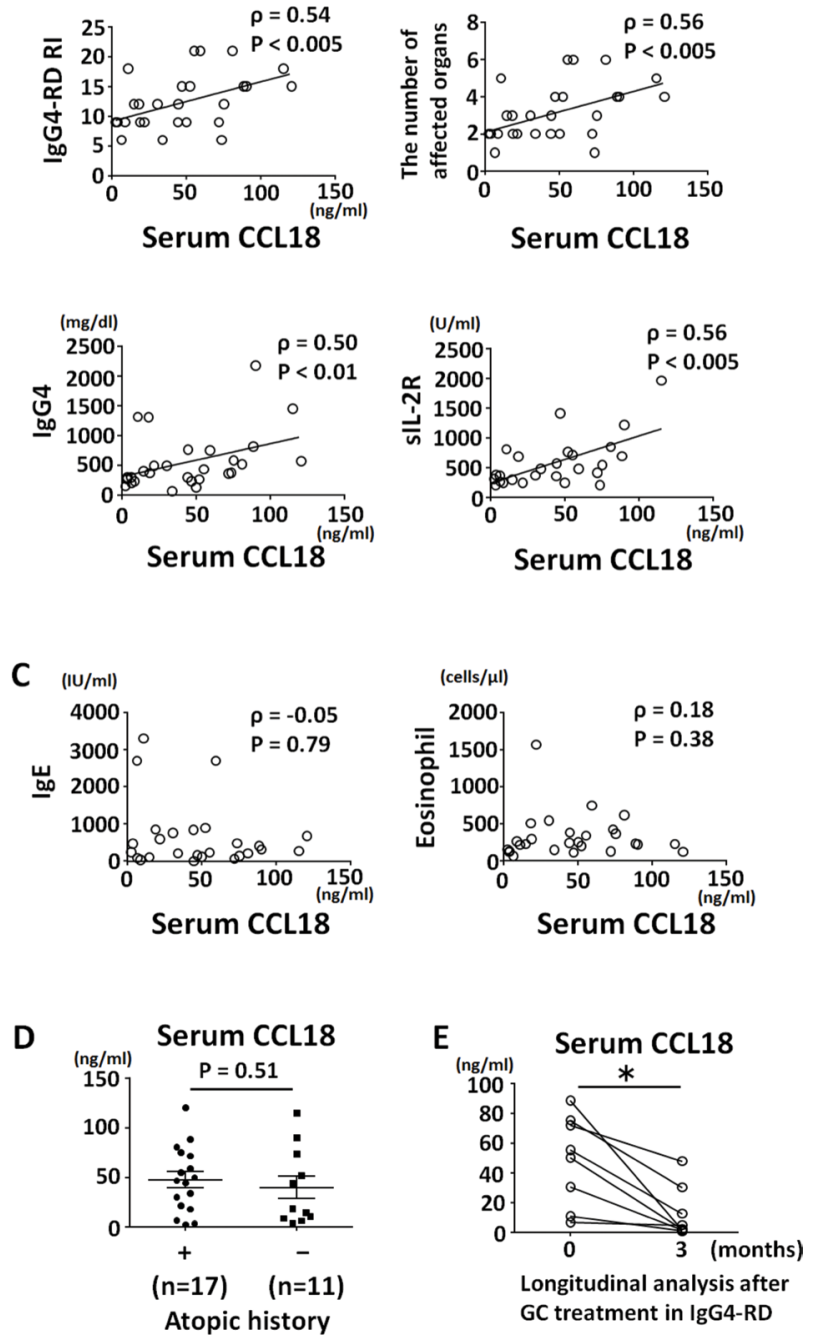

Figure 1 Serum CC-chemokine ligand 18 (CCL18) levels were elevated and correlated with disease activity in IgG4-RD. Serum CCL18 levels (A); correlation between serum CCL18 levels and disease activity (B) and allergic condition (C); correlation between serum CCL18 levels and atopic history (D); and longitudinal analysis of serum CCL18 levels after glucocorticoid treatment (E). Group-wise comparisons were performed using the Mann-Whitney $\mathrm{U}$ test. The correlation between serum CCL18 level and clinical parameters including IgG4-RD responder index; number of affected organs; levels of IgG4, sIL-2R, and IgE; and eosinophil count was analysed using Spearman's correlation coefficient. Differences before and after glucocorticoid treatment were determined using the Wilcoxon rank sum test for paired samples. A two-sided $p$ value $<0.05$ was considered significant. All statistical analyses were performed using GraphPad Prism V.6.0 (GraphPad, La Jolla, California, USA). GC, glucocorticoid; HC, healthy controls; IgG4-RD, IgG4-related disease; sIL-2R, soluble IL-2 receptor.
Takeda Pharmaceutical, AstraZeneca K.K., Eli Lilly Japan K.K, and Novartis Pharma K.K. (more than $\$ 10000$ each).

Ethics approval Ethics Committee of Keio University School of Medicine.

Provenance and peer review Not commissioned; externally peer reviewed.

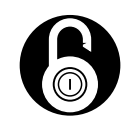

\section{OPEN ACCESS}

Open access This is an open access article distributed in accordance with the Creative Commons Attribution Non Commercial (CC BY-NC 4.0) license, which permits others to distribute, remix, adapt, build upon this work non-commercially, and license their derivative works on different terms, provided the original work is properly cited and the use is noncommercial. See: http://creativecommons.org/licenses/by-nc/4.0/

(c) Article author(s) (or their employer(s) unless otherwise stated in the text of the article) 2018. All rights reserved. No commercial use is permitted unless otherwise expressly granted.

\section{Check for updates}

To cite Akiyama M, Yasuoka $\mathrm{H}$, Yoshimoto $\mathrm{K}$, et al. Ann Rheum Dis 2018;77:1386-1387.

Received 22 July 2017

Revised 12 September 2017

Accepted 6 October 2017

Published Online First 13 October 2017

Ann Rheum Dis 2018;77:1386-1387. doi:10.1136/annrheumdis-2017-212110

\section{REFERENCES}

1 Umehara H, Okazaki K, Kawano M, et al. How to diagnose IgG4-related disease. Ann Rheum Dis 2017;76:e46.

2 Akiyama M, Suzuki K, Yasuoka H, et al. Follicular helper T cells in the pathogenesis of IgG4-related disease. Rheumatology 2017.

3 Fox RI, Fox CM. IgG4 levels and plasmablasts as a marker for IgG4-related disease (IgG4-RD). Ann Rheum Dis 2015;74:1-3.

4 Hoffmann-Vold AM, Tennøe AH, Garen T, et al. High level of chemokine CCL18 Is associated with pulmonary function deterioration, lung fibrosis progression, and reduced survival in systemic sclerosis. Chest 2016;150:299-306.

5 Umehara H, Okazaki K, Masaki Y, et al. Comprehensive diagnostic criteria for lgG4related disease (IgG4-RD), 2011. Mod Rheumatol 2012;22:21-30.

6 Carruthers MN, Stone JH, Deshpande V, et al. Development of an IgG4-RD Responder Index. Int J Rheumatol 2012:2012:1-7.

7 Furukawa S, Moriyama M, Tanaka A, et al. Preferential M2 macrophages contribute to fibrosis in lgG4-related dacryoadenitis and sialoadenitis, so-called Mikulicz's disease. Clin Immunol 2015;156:9-18.

8 Kodelja V, Müller C, Politz 0, et al. Alternative macrophage activation-associated CCchemokine-1, a novel structural homologue of macrophage inflammatory protein-1 alpha with a Th2-associated expression pattern. J Immunol 1998;160:1411-8.

9 Luzina IG, Tsymbalyuk N, Choi J, et al. CCL18-stimulated upregulation of collagen production in lung fibroblasts requires Sp1 signaling and basal Smad3 activity. I Cell Physiol 2006;206:221-8.

10 Tsuboi $H$, Nakai Y, lizuka M, et al. DNA microarray analysis of labial salivary glands in IgG4-related disease: comparison with Sjögren's syndrome. Arthritis Rheumatol 2014;66:2892-9. 